\title{
Uma proposta de processo de Gerência de Configuração baseado no nível 2 do CMMI estagiado para Fábricas de Software Orientadas a Produto
}

\author{
Karine C. A. Oliveira ${ }^{1}$, Alexandre M. L. Vasconcelos ${ }^{1}$ \\ ${ }^{1}$ Centro de Informática - Universidade Federal de Pernambuco (UFPE) \\ Caixa Postal 7851 - 50.732-970 - Recife - PE - Brasil \\ $\{$ kcao, amlv\}@cin.ufpe.br
}

\begin{abstract}
The search for services and products quality improvement has increased in the last few years. To take care of the pressure exerted by the market, the software companies have invested in the professionalization of its operations, using product and project-oriented software factory concepts, and software development and process improvement, using quality models like CMMI. In this context, configuration management is a very important activity in project and product development in a company. This research work presents a configuration management process proposal, which is compliant with maturity and capability level 2 of CMMI Configuration Management process area, applied to product-oriented software factories.
\end{abstract}

Resumo. A busca pela melhoria da qualidade de produtos e serviços oferecidos pelas empresas vem aumentando continuamente nos últimos anos. Para atender à pressão exercida pelo mercado, as empresas de software têm investido na profissionalização de suas operações, como a reestruturação em fábricas de software e a melhoria dos processos de desenvolvimento, usando modelos conceituados, como o CMMI. Neste contexto, a gerência de configuração é uma atividade de extrema importância para o desenvolvimento de projetos e produtos. Este trabalho apresenta a proposta de um processo de gerência de configuração alinhado ao nível 2 de maturidade e capacidade do CMMI, destinado a fábricas de software orientadas a produto.

\section{Introdução}

A busca pela melhoria da qualidade de produtos e serviços fornecidos pelas empresas de software vem aumentando continuamente nos últimos anos. O mercado dos produtos e serviços de software, antes passivo às tecnologias e aos processos das empresas de software, tem-se tornado cada vez mais ativo e exigente: para adquirir um produto ou serviço, são levadas em consideração, entre outras, as variáveis "prazo", "custo", "características" e "qualidade do produto ou serviço", as quais podem ser consideradas como as quatro dimensões mais significativas do gerenciamento de projetos [Junk, 2000].

Analisando estas quatro dimensões, não se pode deixar de mencionar o artigo "Extreme Chaos" [Standish, 2001], do Standish Group [Standish, 2007], onde é feito um resumo do histórico da evolução dos projetos desde o artigo "Chaos Report" [Standish, 1995] até o ano de 2000. Apesar de notarmos uma melhoria no percentual de 
projetos bem-sucedidos, este grupo ainda é uma minoria diante dos projetos desafiadores e os falhos. As características dos clientes vêm mudando ao longo do tempo, e para acompanhar estas mudanças, as empresas de desenvolvimento de software têm investido na profissionalização de suas operações através de várias iniciativas, como a reestruturação da organização e a melhoria dos processos de desenvolvimento de software.

$\mathrm{Na}$ área organizacional, os modelos de fábrica de software têm sido vistos como um meio de aperfeiçoar a produção de software, através da especialização das equipes e da padronização da forma de trabalho [Aaen, 1997]. Na área de processos, as empresas têm seguido diversos modelos de processo para melhorar a qualidade do seu desenvolvimento, integrando a área de desenvolvimento de software com outras áreas do negócio. Esta proposta tem sido a base para a evolução de diversos modelos de processo, como o CMMI - Capability Maturity Model Integration [Chrissis, 2003]. Esses dois grupos de iniciativas envolvem mudanças em todas as áreas relacionadas ao desenvolvimento de software, como as áreas de gestão de projetos e requisitos, engenharia e de suporte, como a gerência de configuração. Esta área, em particular, demanda uma atenção redobrada, para garantir a tranqüilidade na execução do desenvolvimento e entrega dos produtos e serviços pelas empresas.

Este trabalho apresenta a proposta de um processo alinhado ao nível 2 de maturidade [SEI029, 2002] e capacidade [SEI028, 2002] do CMMI para a área de processo de gerência de configuração, destinado a fábricas de software orientadas a produto. A escolha da gerência de configuração vem da necessidade de estruturar esta área de suporte tão critica para o funcionamento de uma fábrica de software orientada a produtos, onde a gestão de versões e o controle de mudanças são tão críticos quanto a gestão de operações.

Além desta seção introdutória, este artigo é composto das seguintes seções: a Seção 2 apresenta uma visão geral da disciplina de gerência de configuração; a Seção 3 apresenta o conceito de fábricas de software e o seu contexto na organização relacionado com a gerência de configuração; a Seção 4 apresenta o processo proposto de gerência de configuração alinhado ao nível 2 do CMMI; a Seção 5 apresenta o relato do estudo de caso realizado com a implantação do processo proposto em uma fábrica de software real. Por fim, a Seção 6 apresenta as conclusões e os trabalhos futuros.

\section{A disciplina de Gerência de Configuração}

A gerência de configuração de software pode ser entendida como uma disciplina que permite manter a evolução de produtos de software sobre controle e, dessa forma, contribuir para satisfazer as restrições de qualidade e prazo [Estublier, 2000]. Esta disciplina passou a ser considerada como tal a partir da chamada "crise de software", quando se constatou que seria necessário analisar outros aspectos para melhorar a qualidade dos softwares produzidos. Ao longo dos anos a gerência de configuração tem evoluído, e atualmente pode ser vista com três grandes objetivos:

1. Gerenciar componentes em repositório, que envolvem o gerenciamento de versões, a modelagem de produtos e o gerenciamento de objetos complexos; 
2. Ajudar os engenheiros em suas atividades rotineiras, orientando-os quanto ao acesso correto no repositório, procedimentos de atualização de itens de configuração e controle de seus espaços de trabalho (workspaces);

3. Fornecer suporte e controle ao processo de desenvolvimento, através do controle de mudanças no software ao longo do tempo.

Segundo [Kasse, 2000], atividades de suporte, como gerência de configuração e garantia da qualidade, nem sempre são vistas como valor agregado pelos gerentes de projeto e desenvolvedores de software. Muitas vezes, são vistas como "overhead" de trabalho para se atingir o objetivo do projeto, entregar o software desenvolvido. Segundo [Guess, 1998], a gerência de configuração é vista como uma força invisível: quando funciona, ninguém sabe que ela está presente. Porém, quando não funciona, as conseqüências podem ser desastrosas.

Uma pesquisa recente do Aberdeen Group [Aberdeen, 2007] realizada com 200 empresas do setor industrial (aeroespacial, manufatura e alta tecnologia), mostrou que a melhoria de qualidade, o time to market (tempo de lançamento de um produto no mercado) e a redução dos custos de desenvolvimento do produto são as principais razões para o crescente investimento das empresas em gerência de configuração, como mostra a Figura 1. Os custos associados ao produto são sensivelmente afetados por problemas de configuração do produto, e podem comprometer a margem de lucro da empresa.

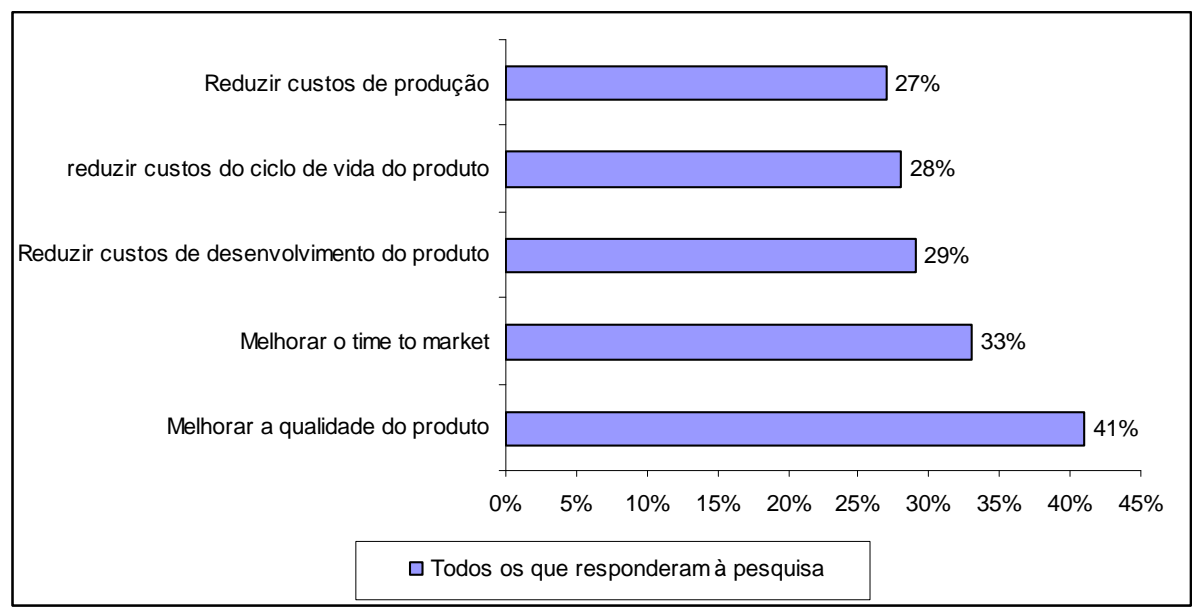

Figura 1. Pressões exercidas para a melhoria de gerência de configuração'

Para as empresas de software, este cenário é bastante familiar. Acompanhando o pensamento de [Guess, 1998], [Kasse, 2000] e [Aberdeen, 2007], alguns aspectos envolvidos em uma gerência de configuração pobre devem ser citados:

- A última versão do código-fonte não está sendo encontrada;

- Um defeito corrigido anteriormente voltou a ocorrer de repente;

- Os testes foram realizados na versão errada do código-fonte;

\footnotetext{
${ }^{1}$ Fonte: Aberdeen Group. The Configuration Management Benchmark Report [Aberdeen, 2007]
} 
- Os programadores estão trabalhando com a versão errada do código-fonte;

- A baseline estabelecida contém as versões erradas dos itens de configuração.

Além dos problemas citados, um problema de gerência de configuração no software normalmente é percebido externamente (pelos clientes finais da empresa), afetando a relação cliente-fornecedor, visto que o cliente questiona claramente o processo de desenvolvimento da empresa, onde a ausência de qualidade fica evidenciada pelos problemas de configuração do software. Além disso, o retrabalho causado por um problema de configuração aumenta ainda mais os custos da empresa no desenvolvimento do software em questão, pois será necessário recuperar a configuração correta do software para disponibilizá-la ao cliente, ou corrigir novamente um defeito que já tinha sido corrigido, o que, se a gerência de configuração não estiver bem definida, tomará tempo da equipe de desenvolvimento, que deveria estar trabalhando em outras atividades. Daí a necessidade de inserir a gerência de configuração no âmbito de uma organização, fazendo com que todos os projetos sejam beneficiados por esta disciplina.

A gerência de configuração pode estar disseminada em uma organização sob duas perspectivas: de projetos e de produtos [Farah, 2004]. A gerência de configuração de um projeto inicia com o estabelecimento de uma baseline dos requisitos, entradas necessárias para o planejamento e execução das atividades do projeto. Através destes requisitos, serão programados os releases do produto que atenderão a estes requisitos. A gerência de configuração do produto, por sua vez, lida com a gestão de todos os releases dos produtos, que contemplam todos os seus itens de configuração e deliverables, atendendo às evoluções solicitadas e correções de erros detectados.

Enquanto a primeira perspectiva (de projeto) é aplicável em organizações orientadas a projeto ou a produtos, a segunda só faz sentido quando a organização é orientada a produto. Quando uma empresa possui estas duas perspectivas, a gerência de configuração do produto passa a administrar também os impactos que os projetos geram nos produtos da empresa, aumentando a complexidade da atividade de gerência de configuração.

\section{Gerência de Configuração em Fábricas de Software}

O conceito de Fábrica de software envolve um ambiente que suporta a produção de software de maneira mais industrializada, adotando as práticas da indústria e engenharia [Lim, 1999]. Embora o conceito de fábrica de software exista há pelo menos 30 anos, a adoção e aplicação deste modelo são recentes e ainda não atingiram grandes escalas.

Desde a descoberta desse novo modelo de trabalho para o desenvolvimento de software, surgiram diversas adaptações do mesmo, com diferentes abordagens, focando ora em ferramentas, ora em processos. Dentre muitos modelos, três se destacam: o modelo japonês, com foco em alta produtividade e qualidade; o modelo europeu, com foco na integração de ambientes de desenvolvimento de software; e o modelo norteamericano, com as abordagens baseadas na experiência e na maturidade da organização [Aaen, 1997]. 
Estas abordagens mostram que o objetivo dos modelos de fábrica tem evoluído através dos tempos buscando a melhoria de processos na organização, para que a fábrica seja capaz de absorver toda a demanda de serviços e produtos sem prejudicar seu funcionamento, e conseqüentemente, a qualidade de seus produtos. Além disso, os processos de uma fábrica devem ser capazes de suportar também os conceitos típicos de fábricas, como a padronização e o controle da produção.

Embora a abordagem da melhoria de processos faça parecer simples a sua execução, é preciso evoluir gradativamente a maturidade da organização, para que ela aos poucos consiga entender sua capacidade, e passe a responder melhor às demandas solicitadas. Neste contexto, a fábrica pode ser um ponto de início da melhoria, e propagar esse processo pelos demais setores da organização onde a fábrica está inserida. Porém, é importante ressaltar a abordagem de negócio das fábricas de software, que pode facilitar ou dificultar a melhoria de processos na organização. Diante disso, seguem duas estruturações organizacionais: fábrica orientada a produtos e fábrica orientada a projetos [Tachizawa, 1997].

\subsection{Contexto das fábricas de software dentro da organização}

Segundo [Fernandes, 2004], as fábricas de software podem estar organizadas de duas formas: uma área da organização, subordinada a outras áreas da própria empresa; ou a própria organização.

No primeiro cenário, a fábrica de software é considerada uma área da organização, que deve possuir metas internas alinhadas ao planejamento estratégico da empresa, e que deve gerar lucro para a organização. Neste cenário, alguns pontos se tornam críticos:

- Deve haver uma definição clara do escopo de trabalho da fábrica, ou seja, as entradas e as saídas esperadas para a realização bem sucedida das atividades da fábrica dentro da organização;

- Devem ser estabelecidos os canais de comunicação com a fábrica, para que não haja a banalização da produção;

- A fábrica deve possuir um programa de atendimento às demandas geradas pelos seus clientes, sejam eles internos ou externos.

Já no segundo cenário, a fábrica pode ser a própria organização, com metas estabelecidas, e composta por diversas áreas, desde a administração da organização até os setores de produção propriamente ditos, como a codificação e especificação de requisitos. Neste cenário, a fábrica passa a estar diretamente ligada aos seus clientes, que são sempre externos, pois ela é a própria organização. $O$ processo de desenvolvimento da fábrica passa a ser composto pelos processos de suas áreas, que devem possuir canais de comunicação.

No contexto da orientação a produtos, ilustrado no cenário 1 da Figura 2, o desenvolvimento da fábrica funciona em torno dos produtos produzidos por ela. Neste caso, a fábrica deve conciliar a rotina de manutenção de seus produtos, seja ela evolutiva ou corretiva, com as demandas geradas por diferentes projetos, que culminam no surgimento ou evolução de funcionalidades no produto. Dessa forma, o produto é 
sempre preservado dentro da fábrica, podendo ser customizado ou parametrizado para os clientes demandadores de projetos. Dentro dessa estrutura de fábrica, é importante citar o papel do gerente de produto, que comanda não apenas o desenvolvimento demandado pelos projetos, mas que garante a integridade do produto que está sendo modificado constantemente.

$\mathrm{Na}$ orientação a projetos, a rotina da fábrica funciona através da execução de diversos projetos em paralelo, como apresenta o cenário 2 da Figura 2, onde os projetos podem ser interdependentes ou reusar componentes entre si, mas todos com começo, meio e fim planejados. Neste caso, não há um produto único que deve ser atualizado simultaneamente pelos projetos executados. A saída da fábrica varia de acordo com a demanda de projetos existentes. Nesta estrutura, a responsabilidade por cada projeto pode ser acumulada por um único gerente de projeto ou distribuída entre um grupo de gerentes.

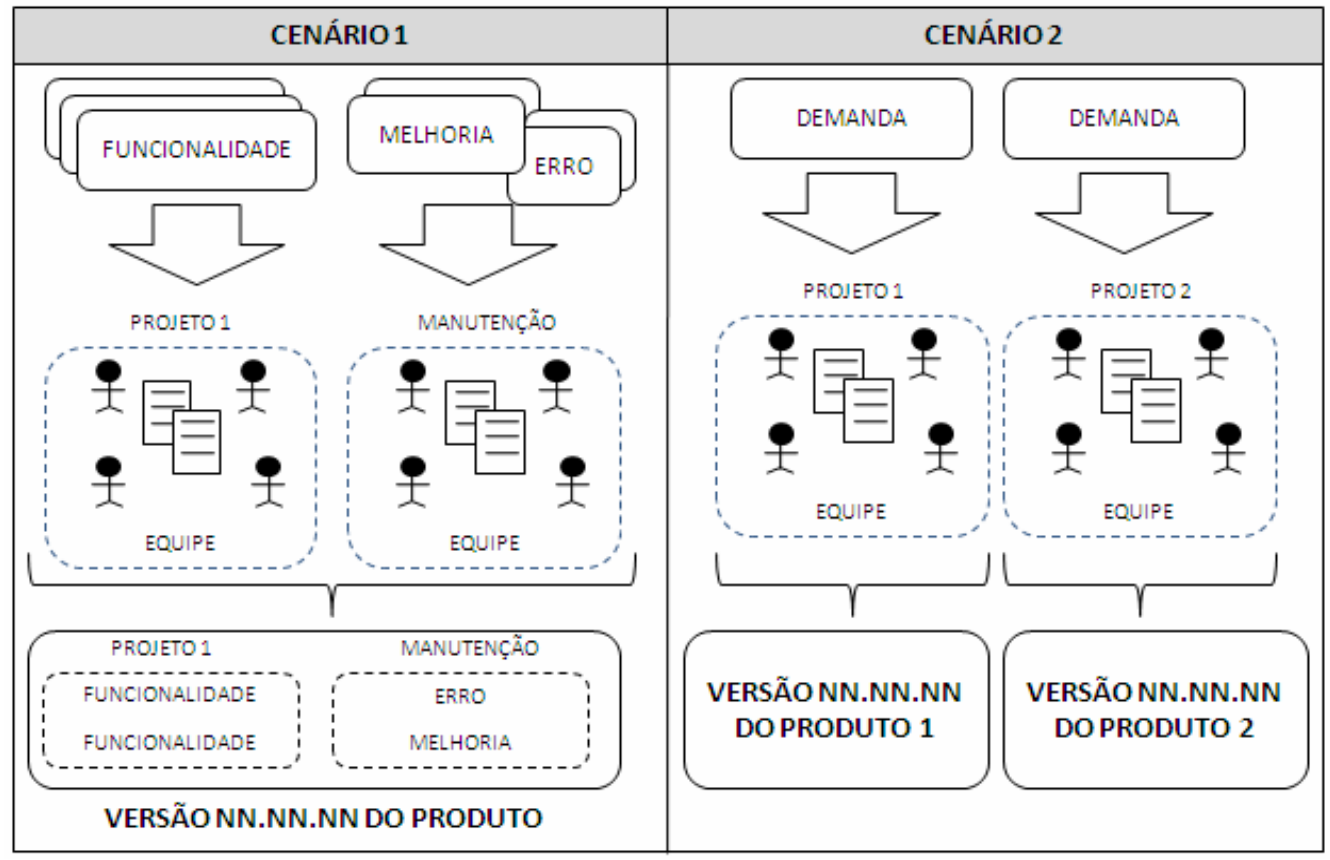

Figura 2. Desenvolvimento orientado a produto (cenário 1) e a projetos (cenário 2)

É importante analisarmos as duas abordagens sob o ponto de vista da gerência de configuração, pois esta área demanda características específicas em cada estrutura organizacional da fábrica. Em uma fábrica orientada a projetos, o planejamento e a execução das atividades da gerência de configuração podem variar completamente entre os projetos executados dentro da fábrica, pois cada um possui características específicas demandadas pelos clientes, causando um trabalho adicional para os gerentes de configuração da fábrica. No entanto, esta característica das fábricas orientadas a projeto possibilita facilmente a paralelização dos recursos de gerência de configuração, ou seja, é possível ter em cada projeto um gerente de configuração dedicado, visto que todas as características do projeto interferem apenas no próprio projeto.

Já nas fábricas orientadas a produto, a realidade é um pouco diferente. Os projetos que geram novas funcionalidades e as manutenções evolutivas e corretivas 
possuem uma gerência de configuração que complementa a do produto. $\mathrm{O}$ controle da configuração do produto deve ser acirrado, para que os projetos não criem conflitos dentro do produto que está sendo modificado e a geração de versões do produto agrega os resultados dos projetos e das manutenções. Diante deste painel, o gerente de configuração passa a ter um papel imprescindível dentro da fábrica, tendo que manter sincronizada a configuração do produto e a configuração de cada projeto dentro da fábrica.

\section{Proposta de processo de Gerência de Configuração}

O processo de gerência de configuração proposto possui o objetivo de sanar os problemas identificados anteriormente nas fábricas de software orientadas a produto, oferecendo uma alternativa de gestão de configuração para este cenário, onde é muito complexo o gerenciamento de tantas demandas paralelas e a manutenção da integridade do produto, bem maior da organização.

O processo baseou-se na experiência da autora na definição e implantação de processos alinhados ao nível 2 de maturidade do CMMI [SEI029, 2002] em uma fábrica de software orientada a produto durante o período entre 2004 e 2006, e encontra-se detalhado em [Oliveira, 2006]. É importante lembrar que o processo pode ser aplicado em fábricas de software independente de elas serem parte da organização ou serem a própria organização, como explicado anteriormente. Porém, o contexto da fábrica vai determinar o nível das responsabilidades no processo, o que será abordado durante a explicação detalhada do processo proposto.

A estrutura do processo proposto está alinhada ao nível 2 de capacidade e baseia-se nas definições usadas pela área de processo de Definição de Processos Organizacionais (OPD), descrita em detalhes no modelo CMMI [Chrissis, 2003]. O processo proposto de Gerência de Configuração é composto de 5 subprocessos, conforme apresenta a Figura 3:

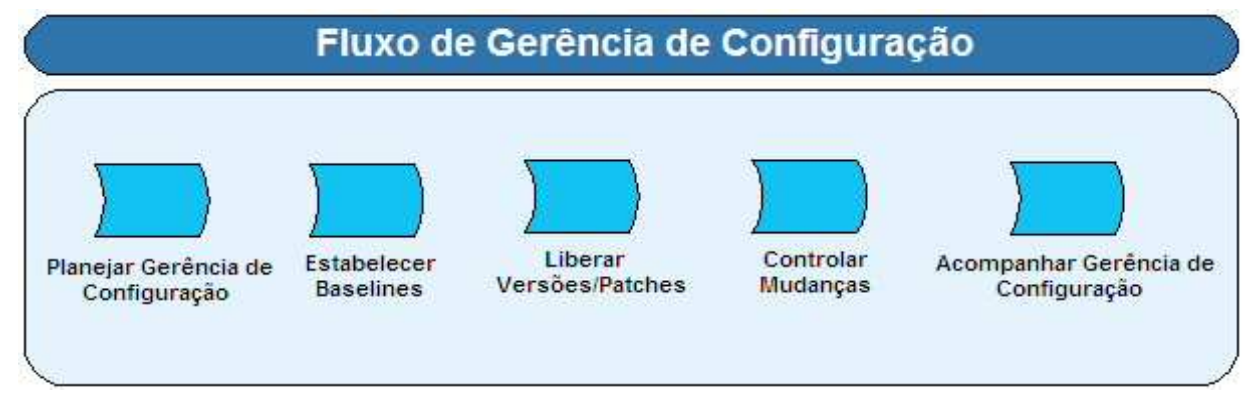

Figura 3. Visão gráfica do processo proposto de gerência de configuração

O objetivo do subprocesso Planejar Gerência de Configuração é englobar todas as atividades de elaboração do planejamento das atividades de gerência de configuração da fábrica de software, tanto para o produto em si como para os projetos que estão vinculados ao produto. É durante o planejamento que os itens de configuração do produto e dos projetos são identificados e as atividades de trabalho das equipes vinculadas à gerência de configuração são definidas. É importante ressaltar que a maioria das informações do planejamento, para uma fábrica de software orientada a 
produto, é perene, estando relacionada ao produto, tendo apenas algumas particularidades variando por projeto.

O subprocesso Estabelecer baselines apresenta as atividades relacionadas ao estabelecimento e manutenção das baselines planejadas no subprocesso 1. Para as fábricas de software orientadas a produto, as baselines podem estar orientadas à versão do produto, visto que ela é o resultado do trabalho das equipes que trabalham na fábrica, independente do projeto no qual elas estão alocadas. Por isso, é importante definir claramente os passos e critérios para entrada dos itens de configuração em uma baseline, para evitar a inconsistência entre as baselines programadas e os itens de configuração previstos em cada uma delas. O Gerente de Configuração deve fazer auditorias de estabelecimento de baseline para garantir a sua integridade. Durante o estabelecimento de uma baseline de código-fonte, pode ser requisitada a geração de uma build interno do produto, para fins de certificação ou testes integrados.

Para o subprocesso Liberar Versões / Patches, a liberação de uma versão ou de um patch está vinculada ao estabelecimento prévio de uma baseline de código para a versão a ser liberada. Este subprocesso propõe as seguintes premissas para liberação de versões ou patches:

- A liberação de uma versão ou patch deve estar condicionada minimamente ao retorno dos testes de certificação do produto: Todas as implementações contidas na versão a ser liberada devem ser testadas para que haja uma garantia mínima da qualidade do produto que está sendo entregue, ou seja, mesmo não havendo na fábrica uma estrutura formal de certificação de produtos, com planos e projetos de teste elaborados, é preciso definir um conjunto mínimo de evidências que garantam que o produto foi testado.

- A liberação de uma versão ou patch do produto deve se basear em uma baseline estabelecida: Quando é autorizada a liberação de uma versão ou patch, o código-fonte que gerou os executáveis, sendo um item de configuração, deve estar em uma baseline estabelecida previamente, ou seja, assim como as baselines estão vinculadas ao planejamento de escopo de uma versão ou patch, a liberação desta versão (ou patch) necessita do estabelecimento de uma baseline contendo os códigos-fontes do produto.

O subprocesso Controlar mudanças pode ser considerado um dos mais críticos dentro do processo proposto, porque, em uma fábrica orientada a produto, as solicitações de mudança para o produto são constantes, tanto para melhorias solicitadas pelos clientes, como os erros encontrados em ambientes de produção, sendo que estes, para este tipo de organização, possuem uma alta prioridade em relação às demais solicitações de mudança. Por isso, é preciso conciliar na fábrica os ciclos de atendimento das melhorias com as correções de erro e os projetos em andamento, visto que todos estes três tipos de atividades são finalizados através das liberações de versões e patches pela fábrica.

O subprocesso Acompanhar Gerência de Configuração engloba as atividades de acompanhamento de status das atividades de gerência de configuração e das auditorias periódicas de configuração que devem ser realizadas dentro da fábrica. A importância deste subprocesso se deve ao fato de que é necessário monitorar 
periodicamente se o processo está sendo executado corretamente na rotina diária das equipes da fábrica, para evitar que as atividades sejam executadas de forma incorreta, prejudicando o sistema de configuração estabelecido na empresa.

\section{Estudo de Caso}

A organização onde foi realizado o estudo de caso foi uma empresa de desenvolvimento de software de São Paulo, com filiais em Recife e Rio de Janeiro. O mercado de atuação desta empresa é o mercado de varejo, através do fornecimento de soluções de automação comercial. A estrutura da organização contempla, dentre outras áreas, uma fábrica de software situada em Recife, que será o objeto de estudo da autora. A fábrica de software desta organização é vista como uma área da organização. A Figura 4 apresenta uma visão geral da estrutura da fábrica e seus relacionamentos com algumas áreas da organização.

A organização possui diversos produtos de software, que são mantidos pela sua fábrica de software em Recife. Para o estudo de caso, foi escolhido 01 produto desenvolvido pela empresa (chamado de produto 1), que é destinado às operações de conciliação eletrônica. Este produto foi desenvolvido em Visual Basic e está instalado em 24 clientes, possuindo atualmente 03 versões em ambiente de produção. Para este produto, foram escolhidos dois projetos:

- Projeto 1-A: projeto de novo desenvolvimento, demandado por um cliente da empresa, que iniciou em 2004 e já está finalizado;

- $\quad$ Projeto 1-B: projeto de manutenção do produto para um cliente da empresa, que iniciou em 2006 e está em andamento.

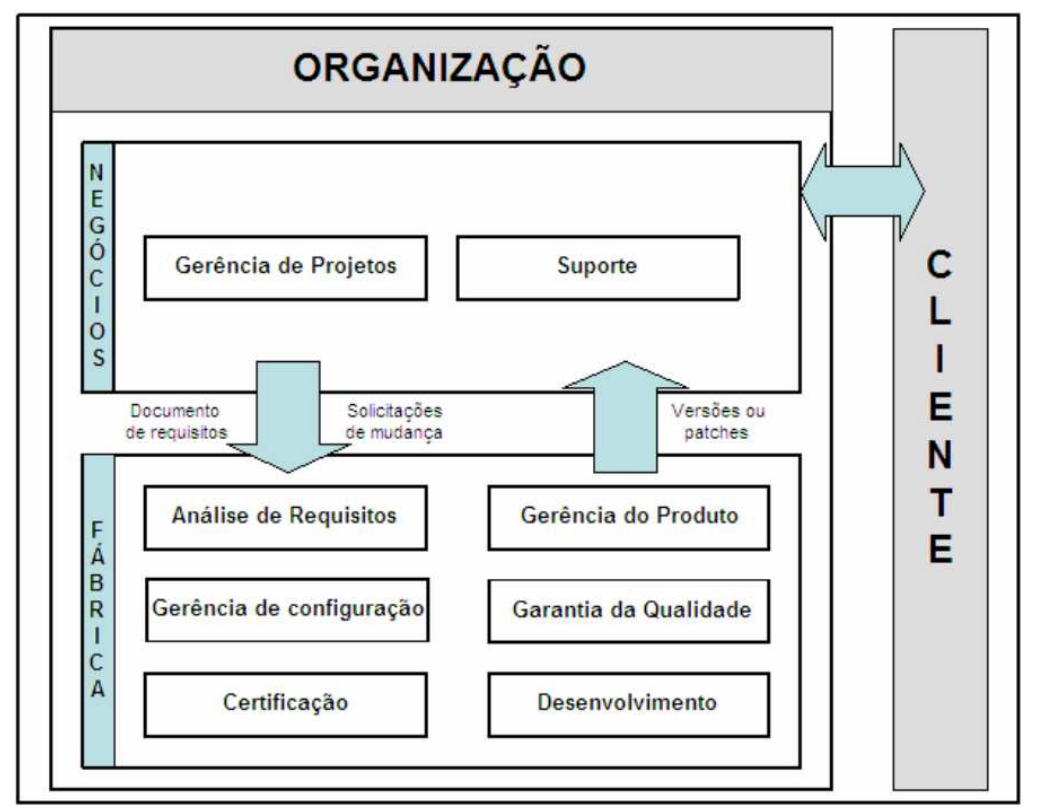

Figura 4. Visão geral da fábrica de software do estudo de caso

A empresa vem investindo em qualidade desde o ano de 2003, e durante o período de 2004 a 2006 participou de um projeto para obtenção do nível 2 de maturidade do CMMI em um grupo de empresas de Pernambuco. Este projeto 
compreendia as atividades de avaliação de escopo da organização, definição e institucionalização dos processos do nível 2, e contou com a participação dedicada da autora em todas as fases. A Figura 5 apresenta o cronograma geral do estudo de caso, com o resumo de todas as atividades realizadas durante o período de aplicação do processo proposto na fábrica de software orientada a produto.

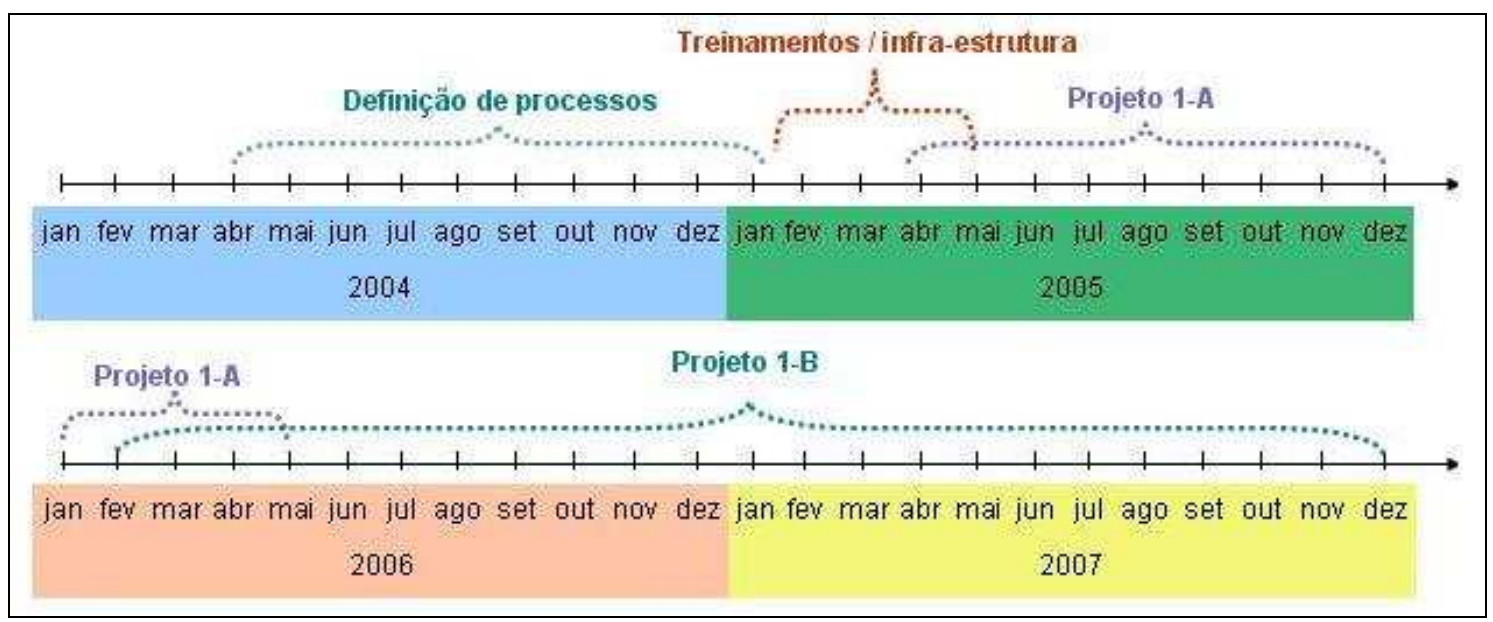

Figura 5. Cronograma do estudo de caso

Para iniciar a institucionalização, foi necessário definir uma política de qualidade para esta área de processo. Com a ajuda da equipe de melhoria de processos, a alta direção seguiu as recomendações do processo proposto e criou um conjunto de diretrizes que deveriam valer para todos os projetos da fábrica. Esta política foi aprovada e publicada para as equipes envolvidas no processo de melhoria. $\mathrm{O}$ treinamento da equipe do produto 1 abordou os conceitos do CMMI e o processo proposto, com detalhamento das atividades que seriam impactadas com a implantação do processo.

O planejamento da gerência de configuração foi uma etapa difícil, devido à falta de experiência da fábrica com a disciplina. Isso foi feito tanto para o projeto $1 \mathrm{~A}$ como para o projeto 1B. A identificação dos itens de configuração obedeceu aos critérios definidos no processo, e foram considerados inicialmente como itens de configuração: código-fonte, parâmetros do sistema, scripts de banco de dados, documentos de requisitos dos projetos, release notes da versão do produto, release notes do patch do produto (quando aplicável), documento funcional do produto.Este último foi criado pela fábrica para documentar todas as evoluções funcionais do produto, e contribuir para a montagem da rastreabilidade do produto (requerimento de outra área de processo em institucionalização).

Foi criado um guia de nomenclaturas para todos os artefatos a serem usados pela fábrica, sejam eles itens de configuração ou não. Neste guia também foi definido o padrão de nomenclatura das versões dos produtos da organização, pois a organização não seguia um padrão de mercado nem possuía um padrão único de versionamento para todos os produtos da empresa.

A configuração das ferramentas de gerência de configuração foi uma atividade bastante complexa para a fábrica, pois durante a implantação do processo sentiu-se a 
necessidade de migração da ferramenta de controle de versões. A fábrica utilizava o Microsoft Visual Source Safe (VSS), e, devido à dificuldade de se gerenciar branches e realizar merges - atividades vitais para a implantação do processo junto à equipe de desenvolvimento, a fábrica optou pelo uso do Concurrent Version System (CVS) com a interface-cliente WinCVS, que supriam as necessidades da organização. Juntamente com esta mudança de ferramenta, veio a necessidade de reorganizar a estrutura de diretórios dos itens de configuração do produto, visto que no VSS não havia uma estruturação clara destes itens.

Para o controle de mudanças, a fábrica já usava a ferramenta Eztrack. Nela eram reportadas todas as solicitações de mudança, tradução para Change Request (CR), tanto pela própria organização como também pelos clientes da empresa. Porém, isso era feito de forma desorganizada, sem seguir um fluxo de trabalho bem definido. Durante a implantação do processo, a ferramenta foi mantida, mas colocada sob um fluxo de trabalho coerente com o processo, e foi definido para a fábrica que, nos procedimentos de check-in dos itens de configuração no repositório, os comentários deveriam sempre conter o número e nome do requisito funcional que estava sendo atendido ou o número da CR do Eztrack que estava sendo corrigida pelo item. Além disso, a ferramenta foi usada como o meio de solicitação de estabelecimento e liberação das baselines. Ao longo da institucionalização, constatou-se que o Eztrack estava dificultando a execução de algumas operações do processo, demandando então a mudança da ferramenta para o Mantis Bug Tracker [Mantis, 2007] e o ajuste do processo.

A maior dificuldade enfrentada pela fábrica durante a execução do subprocesso de controle de mudanças foi a concentração das atividades de análise de impacto sobre o gerente do produto. Foi detectada a sobrecarga do gerente de produto, o que levou à fábrica a flexibilizar novamente a análise de impacto. As análises de impacto eram todas registradas no próprio Eztrack para facilitar o rastreamento da CR, e a auditoria do gerente de configuração. Nela eram informados os participantes da análise de impacto e a decisão tomada, e a CR era atribuída ao desenvolvedor responsável pela correção.

\subsection{Auditorias de qualidade realizadas no processo}

Ao longo da institucionalização do processo, a fábrica contou com a realização das auditorias periódicas de qualidade, executadas pelo engenheiro de qualidade, e das auditorias externas, realizadas por consultores de qualidade do Centro de Estudos Avançados do Recife (CESAR) e pela Integrated System Diagnostics Brasil (ISD Brasil). Ao todo, foram realizadas ao longo da institucionalização 02 auditorias externas, que avaliaram o escopo da melhoria de processos, no qual o produto 1 estava incluído.

Como a fábrica estava trabalhando com a institucionalização dos processos do nível 2 de maturidade, todas as áreas de processo foram avaliadas. Apesar de o escopo ser maior que o objeto deste estudo de caso, o mesmo processo foi implantado em todos os produtos, e o resultado apresentado mostra um painel de aderência do processo à organização. Nos gráficos a serem apresentados, o processo de gerência de configuração recebeu a sigla "CM", baseada na área de processo "Configuration Management" do CMMI. 
$\mathrm{Na} 1^{\mathrm{a}}$ avaliação externa, realizada no segundo semestre de 2005, o foco foi identificar a definição dos processos e o início de sua institucionalização. A avaliação não possuiu um nível de detalhamento requerido em avaliações oficiais do CMMI. Foram definidos os seguintes critérios para avaliação do processo:

- Definição de Processos: o quanto a prática está documentada em relação a como deve ser realizada. Possíveis valores: TD (Totalmente Definido), LD (Largamente Definido), PD (Parcialmente Definido) e ND (Não Definido)

- Institucionalização: o quanto a prática está em uso na organização. Possíveis valores: TI (Totalmente Implementado), LI (Largamente Implementado), PI (Parcialmente Implementado) e NI (Não Implementado).

Conforme apresenta a Figura 6, foi observado que a definição do processo estava bastante alinhada ao nível 2 do CMMI, mas que a fábrica precisaria despender mais esforços para a institucionalização. De fato, ainda no início da institucionalização, o processo estava com muitas falhas de implantação, mas com a ajuda da consultoria foi possível realizar os ajustes necessários e obter um processo mais eficiente.

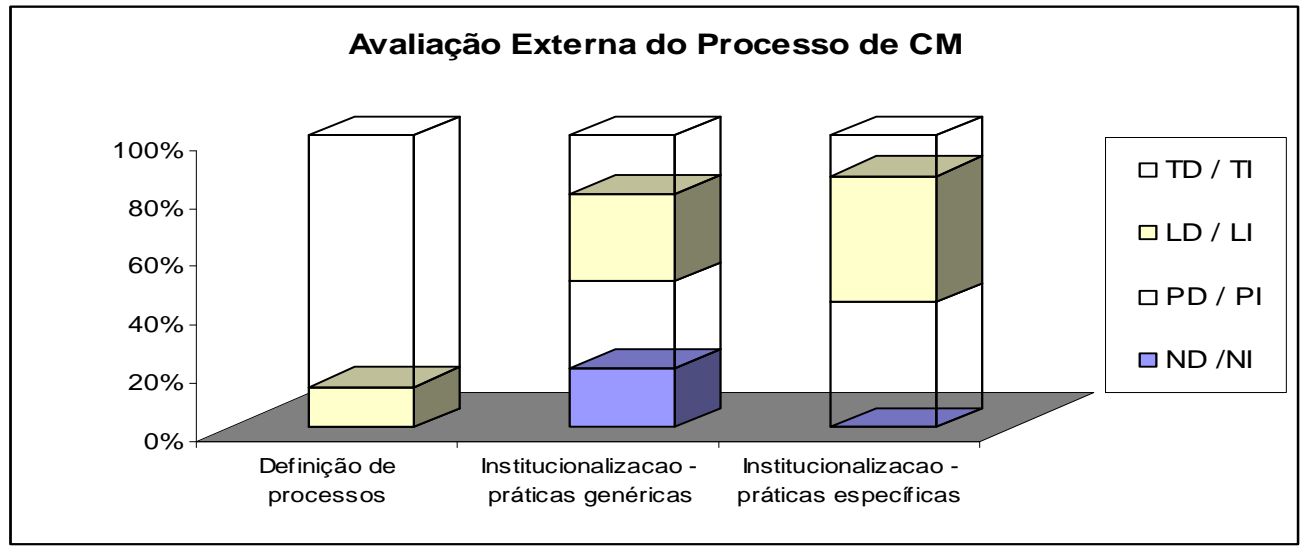

Figura 6. Resultado da $1^{\mathrm{a}}$ auditoria externa do processo de CM

A $2^{\mathrm{a}}$ auditoria externa foi realizada em abril de 2006, ainda durante o processo de consultoria externa. Desta vez, os consultores definiram outros critérios de avaliação:

- Baixo risco (BR): Artefatos diretos presentes para os projetos avaliados, sem "gaps" aparentes;

- Risco médio (MR): Existência de gaps nos artefatos para um ou mais projetos, desalinhamento com entrevistas, práticas recém-implantadas ou /não executadas;

- $\quad$ Alto risco (AR): Artefatos inexistentes ou não adequados para todos os projetos;

- Informação Necessária (IN): Não foi possível analisar a prática por falta de informações ou por falta de tempo.

Nesta auditoria, nem todas as práticas genéricas foram avaliadas, daí a necessidade de se criar a categoria "Informação necessária". A prioridade dada em função do tempo de auditoria foi para as práticas genéricas GP 2.2, 2.5, 2.8, 2.9 e 2.10. Além disso, os processos não foram avaliados em relação à definição. Porém, foi constatado que, mesmo havendo um conjunto de práticas genéricas não avaliadas, a 
institucionalização do processo ainda estava muito aquém de uma avaliação formal (Figura 7).

Durante as avaliações internas realizadas pela fábrica, muitos itens evidenciados nas avaliações externas já eram de conhecimento da alta direção, pois foram identificados anteriormente. Porém, as pessoas entrevistadas durante as avaliações sempre relatavam os benefícios trazidos pelo processo, mesmo possuindo ainda muitas deficiências de institucionalização, pois a existência do controle dos itens de configuração, que antes não era visualizado por eles, trazia uma maior tranqüilidade ao desenvolvimento do produto 1 e demais produtos avaliados. A equipe evidenciou os benefícios trazidos pelo controle de mudanças, que passou a ser padronizado com a utilização adequada do Eztrack, além da criação das baselines, que permitiram à equipe obter um acesso rápido a qualquer versão do sistema sob a gerência de configuração definida para os produtos.

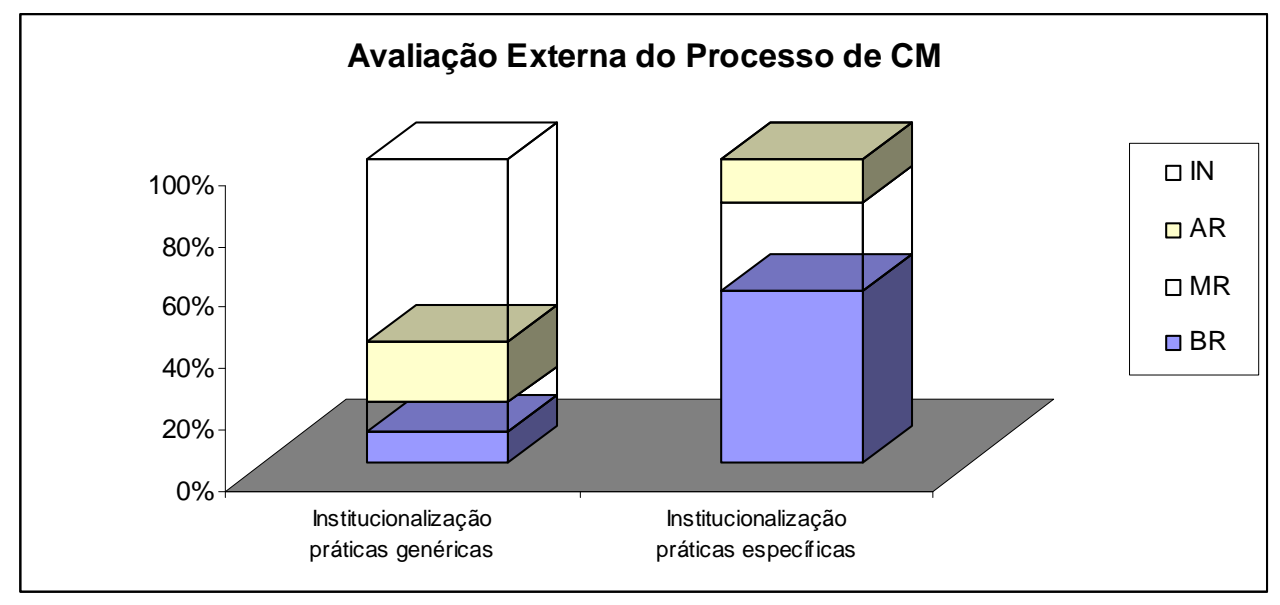

Figura 7. Resultado da $2^{\mathrm{a}}$ auditoria externa do processo de $\mathrm{CM}$

\section{Conclusão e trabalhos futuros}

O processo proposto foi desenhado com o objetivo de promover uma maior integração entre os projetos que afetam um produto dentro de uma fábrica de software, tanto os novos desenvolvimentos como os projetos de manutenção. Através de uma gestão direcionada ao escopo do produto, a gestão de configuração na fábrica passa a conciliar os itens de configuração dos projetos e do produto, e os integra através das baselines do produto.

A incorporação das práticas genéricas e específicas do CMMI tornou o processo proposto mais robusto, com a formalização de atividades críticas da gerência de configuração, como o controle de versões e mudanças. $\mathrm{O}$ estudo de caso realizado por este trabalho funcionou também como um relato de experiência, pois a autora já atuou como gerente de configuração e há 03 anos atua diretamente na definição e implantação de processos em uma fábrica de software.

Através do estudo de caso aplicado em uma fábrica de software orientada a produto, foi possível evidenciar os principais benefícios trazidos pelo processo à organização: 
- Maior controle sobre os itens de configuração, através da documentação dos mesmos em um plano de gerência de configuração e monitoramento realizado pelo gerente de configuração.

- Padronização do controle de mudanças, através da utilização de ferramentas automatizadas para apoiar o processo, auxiliadas pelos procedimentos operacionais de gestão de mudanças definidos para a organização.

- Acesso facilitado às versões do produto ao longo do tempo, obtido através do estabelecimento de baselines e liberação de versões e patches pelo gerente de configuração, conforme definido no processo.

A evolução deste trabalho prevê o aumento da integração do processo proposto com as demais áreas de processo do nível 2 de maturidade do CMMI, permanecendo com o foco nas fábricas de software orientadas a produto. As dificuldades existentes na institucionalização dos processos restantes comprometeram a execução de algumas atividades do processo proposto. A institucionalização das demais áreas de processo foi realizada parcialmente.

Outro trabalho importante de evolução é a inserção definitiva de ferramentas de apoio ao processo nas atividades do processo, o que facilitará ainda mais a implantação do mesmo em uma fábrica de software. Hoje o processo sugere o uso de ferramentas, mas não é obrigatório usá-las. Dependendo de como o processo seja implantado, ele pode se tornar lento, o que comprometeria o sucesso da implantação. Se passarmos a inserir obrigatoriamente o uso de algumas ferramentas de apoio ao processo, a lentidão não será mais uma possibilidade durante a implantação do processo.

O ajuste do processo proposto para as linhas de produto de software é um passo importante para a evolução deste trabalho, visto que essa área de trabalho demanda uma gerência de configuração ainda mais detalhada que a deste trabalho, pois além de controlar os produtos com suas manutenções e novos desenvolvimentos, o gerente de configuração deve se preocupar com os ativos, ou seja, os componentes que são considerados o core da família de produtos e que precisam ser evoluídos e corrigidos assim como é feito com os produtos.

\section{Referências}

Aaen, I., Botcher, P. e Mathiassen, L. (1997) "The Software Factory: Contributions and Illusions." In: Proceedings of the Twentieth Information Systems Research Seminar in Scandinavia, Oslo, 1997.

Aberdeen Group, Inc. (2007) "The Configuration Management Benchmark Report Formalizing and Extending CM to Drive Quality”. Massachusetts, February 2007.

Chrissis, M. B., Konrad, M. e Shrum, S. (2003) "CMMI: Guidelines for 1Process Integration and Product Improvement”. Pearson Education, 2003.

Esublier, J. (2000) "Software Configuration Management: A Roadmap". In Proceedings of the Conference of The Future of Software Engineering, p.279-289, June 04-11. Limerick, Ireland, 2000. http://doi.acm.org/10.1145/336512.336576, último acesso junho/2007. 
Farah, J. (2004) "Changes: The Crossroads Between Project CM and Product CM". CM Crossroads, October, 2004. http://www.cmcrossroads.com/content/view/6727/238/, último acesso - abril/2007.

Fernandes, A. A. e Teixeira, D. S. (2004) "Fábricas de Software: Implantação e Gestão de Operações". São Paulo - Atlas, 2004.

Guess, V. (1998). "What's New in CM?" Institute of Configuration Management Scottsdale, 1998.

http://www.icmhq.com/newsviews/Whats\%20New\%20in\%20CM.html, último acesso - junho/2007.

Junk, W. S. (2000) "The Dynamic Balance Between Cost, Schedule, Features, and Quality in Software Development Projects". Moscow, 2000.

Kasse, T. e McQuaid, P. A. (2000) "Software Quality Professional". American Society for Quality. September, 2000.

http://www.asq.org/pub/sqp/past/vol2_issue4/mcquaid.html, último acesso junho/2007.

Lim, N., Ang, S. K. J. e Pavri, F.N. (1999) "Diffusing Software-based Technologies with a Software Factory Approach for Software Development: A Theoretical Framework". Department of Decision Sciences, Faculty of Business Administration, National University of Singapore, Republic of Singapore, 1999.

Mantis Bug Tracker (2007). http://www.mantisbt.org/, último acesso - maio/2008.

Oliveira, K. C. A. (2007) "Um processo de Gerência de Configuração baseado no nível 2 do CMMI estagiado para Fábricas de Software Orientadas a Produto". Dissertação de Mestrado, Universidade Federal de Pernambuco, Agosto 2007.

Software Engineering Institute - CMU/SEI-2002-TR-028 (2002) "Capability Maturity Model Integration, Version 1.1 - CMMI for Software Engineering (CMMI-SW, V1.1) Continuous Representation”. Carnegie Mellon University, August 2002.

Software Engineering Institute - CMU/SEI-2002-TR-029 (2002) "Capability Maturity Model Integration, Version 1.1 - CMMI for Software Engineering (CMMI-SW, V1.1) Staged Representation”. Carnegie Mellon University, August 2002.

The Standish Group International (2001) "Extreme CHAOS 2001”. February 2001. http://www.vertexlogic.com/processOnline/processData/documents/pdf/extreme_cha os.pdf, último acesso - junho/2006.

The Standish Group Web Site (2007), http://www.standishgroup.com/, último acesso junho/2007.

The Standish Group International (1995) "Chaos Report (1994)". http://www.standishgroup.com/sample_research/chaos_1994_1.php, último acesso junho/2007.

Tachizawa, T. e Scaico, O. (1997) “Organização Flexível: Qualidade na gestão por processos”. São Paulo - Atlas, 1997. 